\title{
Anti-Inflammatory and Immunomodulatory Effects of Barberry (Berberis vulgaris) and Its Main Compounds
}

\author{
Rasool Nasiri Kalmarzi, ${ }^{1}$ Seyyed Nima Naleini, ${ }^{2}$ Damoon Ashtary-Larky, ${ }^{3}$ Ilaria Peluso $\mathbb{D},{ }^{4}$ \\ Leila Jouybari, ${ }^{5}$ Alireza Rafi, ${ }^{6}$ Fereshteh Ghorat, ${ }^{7}$ Nishteman Heidari, ${ }^{2}$ Faezeh Sharifian, ${ }^{2}$ \\ Jalal Mardaneh $\mathbb{D}^{8},{ }^{8}$ Paola Aiello, ${ }^{4,9}$ Sobhan Helbi, ${ }^{10}$ and Wesam Kooti ${ }^{1}{ }^{1}$ \\ ${ }^{1}$ Lung Diseases \& Allergy Research Center, Research Institute for Health Development, Kurdistan University of Medical Sciences, \\ Sanandaj, Iran \\ ${ }^{2}$ Student Research Committee, Kurdistan University of Medical Sciences, Sanandaj, Iran \\ ${ }^{3}$ Nutrition and Metabolic Diseases Research Center, Ahvaz Jundishapur University of Medical Sciences, Ahvaz, Iran \\ ${ }^{4}$ Council for Agricultural Research and Economics (CREA), Research Centre for Food and Nutrition, Via Ardeatina 546, \\ 00178 Rome, Italy \\ ${ }^{5}$ Nursing Research Center, Golestan University of Medical Sciences, Gorgan, Iran \\ ${ }^{6}$ Student Research Committee, School of Nursing \& Midwifery, Shahid Beheshti University of Medical Sciences, Tehran, Iran \\ ${ }^{7}$ Traditional and Complementary Medicine Research Center, Sabzevar University of Medical Sciences, Sabzevar, Iran \\ ${ }^{8}$ Department of Microbiology, School of Medicine \& Student Research Committee, Gonabad University of Medical Sciences, \\ Gonabad, Iran \\ ${ }^{9}$ Department of Physiology and Pharmacology "V. Erspamer", La Sapienza University of Rome, Rome, Italy \\ ${ }^{10}$ Student Research Committee, Dezful University of Medical Sciences, Dezful, Iran
}

Correspondence should be addressed to Wesam Kooti; wesamkooti@gmail.com

Rasool Nasiri Kalmarzi and Seyyed Nima Naleini contributed equally to this work.

Received 19 March 2019; Accepted 5 September 2019; Published 19 November 2019

Academic Editor: Francisco J. Romero

Copyright (c) 2019 Rasool Nasiri Kalmarzi et al. This is an open access article distributed under the Creative Commons Attribution License, which permits unrestricted use, distribution, and reproduction in any medium, provided the original work is properly cited.

Berberis vulgaris is a well-known herb in Iran that is widely used as a medicinal plant and a food additive. The aim of this study was to investigate the anti-inflammatory and immunomodulatory effects of Barberry and its main compounds. This narrative review was conducted by searching keywords such as B. vulgaris, Barberry, immunomodulatory, anti-inflammatory, medicinal herbs, plants, and extract, separately or combined in various databases, such as Web of Sciences, PubMed, and Scopus. According to the inclusion and exclusion criteria, just English language articles, which reported effective whole plants or herbal compounds, were included. 21 articles were reviewed in this study. In the in vivo models (mice, rats, and human cells) and in the in vitro models (some organ cells such as the spleen, kidney, blood, and brain), B. vulgaris and its main components showed anti-inflammatory effects in both models. The main mechanisms were the shift of cell immune response to Th2, $\mathrm{T}$ reg induction, inhibition of inflammatory cytokines (IL-1, TNF, and IFN- $\gamma$ ), and stimulation of IL-4 and IL-10. The induction of apoptosis in APCs and other effector cells was another important mechanism.

\section{Introduction}

Medicinal plants can change the body's physiological or pathological mechanisms to prevent or treat diseases. These plants have been used widely from ancient ages for medical purposes.
Nowadays, easy access, low cost, and the prevailing belief in the low side effects have led to a dramatic increase in the use of these plants compared to chemical medications $[1,2]$. In Iran, the use of medicinal plants is also significantly increased $[3,4]$. Medicinal plants can be used for a variety of purposes, 
including gastroenterology [5], headache and migraine [6], reproductive disorders [7], diabetes [8, 9], hyperlipidemia $[10]$, stress and depression $[11,12]$, liver disorders $[13,14]$, and nervous system disorders [15]. Of course, the use of these drugs also has disadvantages, including deficiencies and lack of experiments for purity, health effects, or teratogenicity [16].

Berberis vulgaris is a common herb in Iran (called Barberry) and other countries that widely used it as a medicinal plant and its fruit as a food additive. The scientific classification of B. vulgaris is given in Table 1 [17]. This shrub plant with a height of 1 to 3 meters is barbed with yellow wood and ovoid leaves and has hanging yellow flowers that ultimately turn to pulled reddish fruits with a length of 7 to $10 \mathrm{~mm}$ and a width of 3 to $5 \mathrm{~mm}$. These fruits come ripening in the end of summer and autumn and are edible. They also have a sour taste and are rich in vitamin C [18-20]. This plant is found in regions such as north of America and central and southern Europe, and south of Asia [21,22]. The various parts of this plant, including stems, roots, fruits and leaveshave been used in Iran and other countries as traditional medicine [23]. In traditional medicine, this plant is used in several purposes, including cleansing of renal stones and urinary tract diseases and gastrointestinal, liver, and gallbladder diseases as well as a circulatory system stimuli [24-26]. Some traditional uses of Barberry are listed in Table 2.

About 22 alkaloid compounds have been identified in the roots, the leaves, and the fruits of Barberry [27]. Studies about the chemical components of the extract of this plant show that alkaloids with an isoquinoline core such as protoberberine, berberamine, tetrandrine, chondocurine, and palmatine are among the important contents of Barberry. In the quantitative HPLC (high-performance liquid chromatography) analysis of the principal alkaloids of the root, shell, and stem of B. vulgaris, berberine and barbramine were reported $1.24 \%$ and $2.5 \%$, respectively. The anti-inflammatory and immunosuppressive properties of these compounds are very important [28-31]. The fruits, flowers, and seeds of this plant contain significant amounts of phenolic compounds (including anthocyanin and carotenoid pigments), pectin, oleoresin, vitamin $\mathrm{C}$, and organic acids such as chelidonic acid, resin, and tannin [18, 20, 32, 33]. The fruits of this plant also have a sour taste and contain dextrose, malic acid, tartaric acid, and citric acid. Barberry extract contains flavonoids such as quercetin, chrysanthamine, hyperoside, dolphinidin-3-O-beta-D-glucoside, pelargonin, petunidin3-O-beta-D-glucoside, alpha tocopherol, and beta-carotene (Figure 1) [34, 35]. Some of the important compounds found in Barberry are listed in Table 3. For Barberry, many properties are mentioned. In various studies, some pharmacological effects, such as antioxidant and cytoprotective properties [36], inhibition of vascular permeability [37] and epidermal growth factor (EGF) [38], and anticholinergic and antihistaminergic properties [18], for anthocyanins and Barberry fruits are mentioned. The antioxidant activity of Barberry is such that it reduces the survival of cancer cells, and this property is probably due to phenolic compounds and flavonols in the Barberry plant [39, 40].

Studies have shown that alkaloids in this plant increase immunity through $\mathrm{T}$ cells $[41,42]$. Berberine in the root of
TABle 1: Scientific classification of B. vulgaris.

\begin{tabular}{lc}
\hline Kingdom & Plantae \\
\hline Order & Ranunculales \\
Family & Berberidaceae \\
Genus & Berberis \\
Species & B. vulgaris \\
\hline
\end{tabular}

Barberry has anticonvulsant, sedative, and diuretic effects [43]. Also, the berberine in Barberry shows the elimination activity of the $\mathrm{ONOO}(-)$ and $\mathrm{NOO}(2)(-)$ radicals that can contribute to oxidative damage reduction [44]. The extract of this plant is effective in inhibiting activating protein 1 (AP1) of human hepatoma cells [45]. However, the consumption of high levels of alkaloid in this plant (berberine) can cause respiratory paralysis, but death from the high consumption of this plant has not been reported so far. Barberry, by controlling the ACE enzyme (angiotensin converting enzyme) in the brain or by antioxidant property, can reduce the symptoms of Parkinson's disease. Barberry extract inhibits monoamine oxidase A (MAO-A), thus increasing the level of monoamines such as epinephrine and dopamine in the brain, which has an antidepressant effect $[28,43]$. Some of the important compounds of this plant are mentioned in Table 3.

Since access to and use of medicinal plants are very easy today, extensive studies on these compounds are important in order to understand their benefits and side effects and can be used to better understanding and explanation of the status of these medications in the community's health. The aim of this study was to investigate the anti-inflammatory and immunomodulatory effects of Barberry and its main compounds.

\section{Methodology}

This narrative review studied the main research performed on anti-inflammatory and immunomodulatory effects of B. vulgaris. Keywords such as B. vulgaris, Barberry, immunomodulatory, anti-inflammatory, medicinal herbs, plants, and extract were searched separately or combined in various databases, such as Web of Sciences, PubMed, and Scopus.

According to the inclusion and exclusion criteria, just English language articles, which reported effective whole plants or herbal compounds that performed standard laboratory tests, were included. Unrelated articles that studied other plants were excluded. The titles and abstracts of the studies were evaluated independently by two authors according to the inclusion and exclusion criteria. Data extracted from various articles were included in the study and entered into a check list that included some information: Publication year, authors' name, model type, concentration or dose of extract, and mechanisms of action (if reported).

\section{Results}

21 articles were reviewed in this study. Details of the studies are presented in Table 4. In the following, we will refer to the most important observations of these studies: 
TABLE 2: Some traditional uses of B. vulgaris.

\begin{tabular}{|c|c|c|c|}
\hline System & Effect & Part of the plant & Method of use \\
\hline \multirow{3}{*}{ Cardiovascular } & Antihypertensive & Dried leaves & Injection \\
\hline & Antiedema & Stem shell & Boiled \\
\hline & Varicose vein treatment & Root & Boiled \\
\hline \multirow{7}{*}{ Gastrointestinal } & Choleretic & Dried whole plant & Injection \\
\hline & Cholagogue & Root & Aqueous extract \\
\hline & Diarrhea & Root & Root \\
\hline & Bowel movement & Dried root shell & Boiled \\
\hline & Liver and gallbladder disorders & Dried root shell & Root \\
\hline & Intestinal ulcers & Root & Root \\
\hline & Hepatitis & Dried root shell & Boiled \\
\hline \multirow{3}{*}{ Endocrine } & Dysmenorrhea & $\begin{array}{c}\text { Fruit } \\
\text { Dried root }\end{array}$ & Aqueous extract \\
\hline & Menorrhagia & Root & Aqueous extract \\
\hline & Contraceptive & Root & Aqueous extract \\
\hline \multirow{3}{*}{ Immune system } & Anti-inflammatory & Dried root & Root \\
\hline & Rheumatoid arthritis & Dried root shell+stem shell & Boiled \\
\hline & Gout & Flower & Boiled \\
\hline \multirow{2}{*}{ Central nervous system } & Reduce fever & Dried fruit & Aqueous extract \\
\hline & Sedative & Dried root & Root \\
\hline \multirow{3}{*}{ Renal } & Diuretic & Dried root & Boiled \\
\hline & Kidney inflammation & Dried root & Root \\
\hline & Nephritis & Dried root shell & Boiled \\
\hline
\end{tabular}

In the study of W-C. Lin and J-Y. Lin, anti-inflammatory effects of berberine were investigated in nonobese diabetic (NOD) rats with spontaneously developed type 1 diabetes. The results showed that type 1 diabetes alone causes inflammation in some visceral organs. The administration of berberine reduced spontaneous thymus and spleen inflammation in mice. The secretion of IL-6 by splenocytes in the presence of Con A in NOD mice was significantly higher than that of ICR mice. Berberine administration (especially at high doses of $500 \mathrm{mg} / \mathrm{kg} \mathrm{BW;} 20 \mathrm{~g}$ mouse/day) reduced ratios of the Th1 (IL-2)/Th2 (IL-4) cytokines expression in NOD mice splenocytes in the absence/presence of LPS in a preventive way [46]. In the study of Lee et al., the pulmonary inflammation process was simulated by stimulating pulmonary factors. Increased levels of inflammatory cytokines such as IL- $1 \mathrm{~b}$ and TNF- $\alpha$ are associated with pulmonary inflammation. This study showed that different inflammatory factors such as lipopolysaccharide, 12-o-tetradecanoylphorbol-13-acetate, hydrogen peroxide, okadaic acid, and ceramide induced the production of IL-1b and TNF- $\alpha$ in human pulmonary epithelial cells (A-549), fibroblast (HFL1), and lymphoma cells. However, the result showed that Berberine suppressed inflammatory factors produced due to the production of TNF- $\alpha$ and IL- $1 \mathrm{~b}$ in human pulmonary cells [47]. In the study of W-C. Lin and J-Y. Lin, the effects of berberine on the expression of the inflammatory cytokines gene in the initial splenocyte of mice, in the presence and absence of lipopolysaccharide (LPS), were investigated in four experimental models under laboratory conditions. In the initial splenocyte of mice, in the absence and presence of LPS, the anti-inflammatory potential of berberine was reported. A study conducted by Marinova et al. on tubulointerstitial nephritis (TIN) model rats showed that the severity of pathologic damage in TIN rats treated by berberine was significantly lower than that of the control group. In these rats, berberine reduced the number of TCD8+ and TCD4+ lymphocytes. The number of these cells in the peripheral blood is reduced by treatment with berberine and also reduces the infiltrated cells in the kidney [48].

Yan et al. investigated berberine effects on intestinal injury induced by DSS (dextran sulfate sodium) as well as on rat colitis and showed that berberine improved weight loss in rats induced by DSS, as well as the activity of myeloperoxidase, inflammatory scars, and colon injury. In addition, berberine inhibited the production of proinflammatory cytokines such as TNF- $\alpha$, IFN- $\gamma$, and IL-17 in colon macrophages and epithelial cells in DSS mice [49]. A study by Jiang et al. was conducted to evaluate the protective effects of berberine on neural cells of the brain parenchyma in EAE mice, and the results showed that berberine can reduce MMP9 activity in the brain of EAE mice and, by reducing the expression of MMP9, causes reducing laminin decomposition and thereby preserving brain blood barrier (BBB) that results in a decrease in the number of inflammatory cells infiltrated in the brain and a reduction in the expression of cytokines and chemokines in the brain [50]. In another study, $\mathrm{Hu}$ et al. showed that treatment with berberine suppressed the pathological changes caused by the CIA. In the Aziz study, 
<smiles></smiles>

Berbamine<smiles>COc1cc2c(cc1OC)-c1cc3ccc(OC)c(OC)c3c(=O)n1CC2</smiles>

Pal matine<smiles>O=C1C2=C(CCC3=C1N1CCc4cc5c(cc4C1C3)OCCO5)OCCO2</smiles>

Oxyberberine<smiles>COc1ccc2cc3[n+](cc2c1OC)CCc1cc2c(cc1-3)OCO2</smiles>

Berberine<smiles>CC1(C)CCC2(C(=O)O)CC[C@H]3C(CCC4[C@@]3(C)CC[C@H]3C(C)(C)[C@H](O)CC[C@]43C)C2C1</smiles>

Oleanolic acid<smiles>CCCCCCCCC(=O)O</smiles>

Malic acid<smiles>COc1ccc2cc3n(c(=O)c2c1OC)CCc1cc2c(cc1-3)OCO2</smiles>

Berlambine

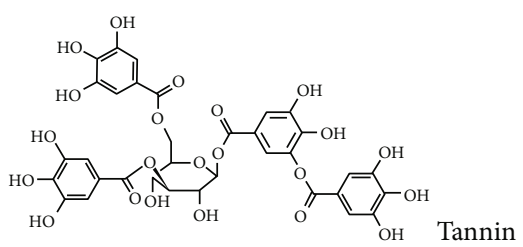<smiles>O=C1O[C@H]([C@H](O)CO)C(O)=C1O</smiles><smiles>O=C(O)CC(O)(CC(=O)O)C(=O)O</smiles>

Citric acid

Figure 1: Structure of some important compounds of B. vulgaris.

TABLE 3: Important compounds of B. vulgaris.

\begin{tabular}{lcc}
\hline Compound & Nature & Part of the plant \\
\hline Acanthine & Alkaloid & Root, root shell, stem shell, leaves, sprout \\
Berbamine & Alkaloid & Root, stem shell, fruit \\
Berberine & Alkaloid & Root, stem, fruit \\
Berlambine & Alkaloid & Root \\
Bervulcine & Alkaloid & Root \\
Columbamine & Alkaloid & Root, stem shell \\
Tannin & Tannin & Fruit \\
Pectin & Carbohydrate & Fruit \\
Delphinidin-3-o-beta-d-glucoside & Flavonid & Leaves \\
Ascorbic acid & Vitamin & Fruit, leaves \\
Palmatine & Alkaloid & Root, stem shell, fruit \\
Quercetin & Flavonid & Leaves \\
Petunidin-3-o-beta-d-glucoside & Flavonid & Fruit \\
Malic acid & Alkane to c4 & Fruit \\
Vitamin K & Vitamin & Leaves \\
Alpha-tocopherol & Oxygen & Leaves
\end{tabular}




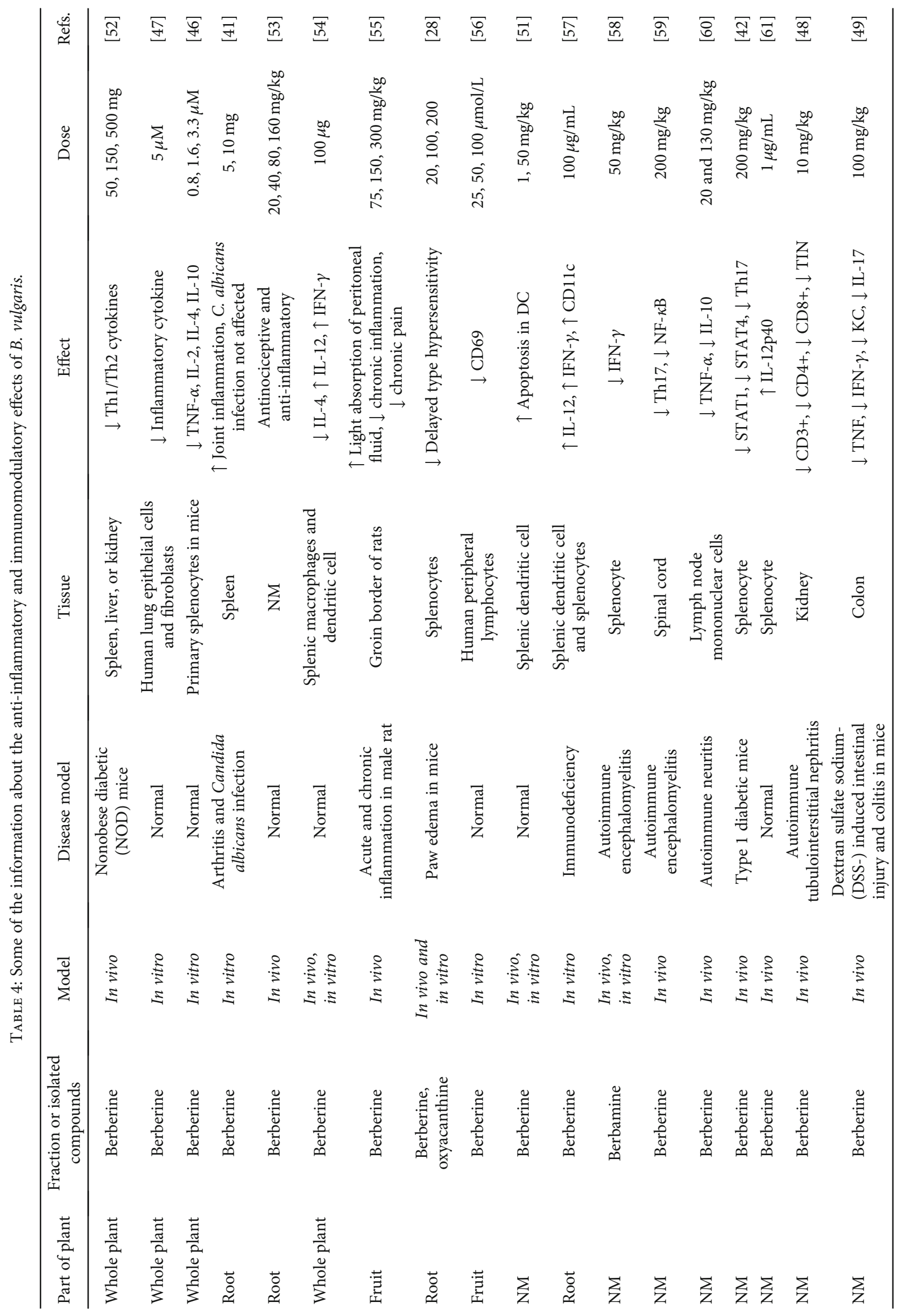




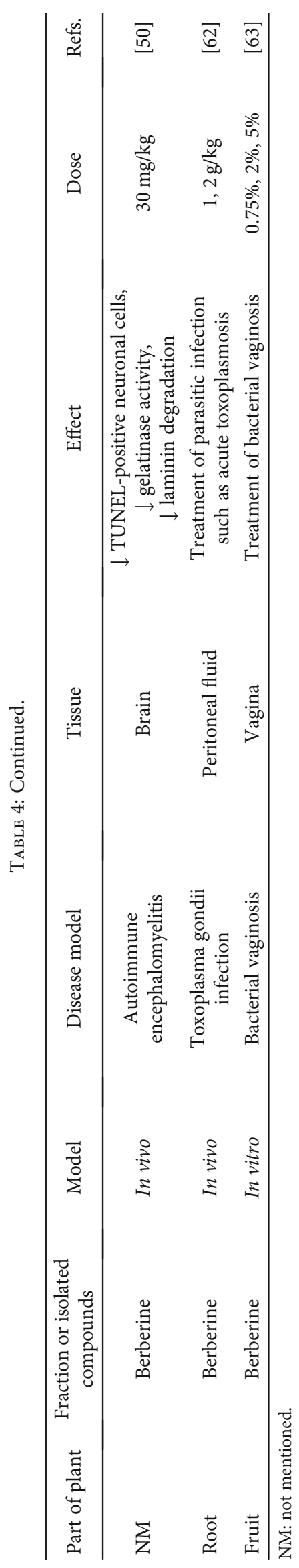


was found that NO levels in the treated B. vulgaris cells were $5 \%$ lower than the control group (no treatment was applied in this group). In the study of $\mathrm{Hu}$ et al., berberine treatment improved EAN symptoms in affected rats [51].

\section{Discussion}

In this study, 21 articles were reviewed. In the in vivo models, mice, rat, and human cells, and in the in vitro models, some organ cells such as the spleen, kidney, blood, and brain were used. In this section, we mention the most important mechanisms of the effect of $B$. vulgaris and its important compounds, including berberine.

In the study of $\mathrm{W}-\mathrm{C}$ Lin and J-Y Lin, the antiinflammatory effects of berberine were attributed to a reduction in TNF- $\alpha$, IL- 6 , and IL-1b cytokines. The use of berberine in NOD mice was positively correlated with LPS-stimulated IL-10/IL-1b and Con A-stimulated IL-10/TNF- $\alpha$. This effect was particularly higher at high doses $(500 \mathrm{mg} / \mathrm{kg} \mathrm{BW;} 20 \mathrm{~g}$ mouse/day). In the confirmation of this finding, Lee et al. showed that berberine reduces the inflammatory factors induced by the production of TNF- $\alpha$ and IL-1b in human pulmonary cells. Berberine inhibited this mechanism by inhibiting Ik-Ba phosphorylation. Berberine also inhibited the expression of cyclooxygenase 2 (COX2) by the regulation of AP-1 [47]. In the study of W-C Lin and J-Y Lin, change in the expression of Th1 (TNF- $\alpha$ ) and Th2 (IL-4) cytokines and the shift of Th1/Th2 to Th2 and further increase in the expression of IL-10 and IL-4 were known as the effective processes in the immunomodulatory activity of berberine [46]. Yan et al. showed that berberine improved myeloperoxidase activity, inflammatory scars, and colon damage. In addition, berberine inhibited the production of proinflammatory cytokines such as TNF- $\alpha$, IFN- $\gamma$, and IL-17 in colon macrophages and epithelial cells in DSS-treated mice [49]. In the study of Ren et al., berbamine altered the response of autoreactive $\mathrm{T}$ cells by two ways: on one hand, by inhibiting the nuclear factor of activated T cells (NFAT), it reduced the T cells proliferation; on the other hand, it changed the cytochrome profile of encephalitogenic $\mathrm{T}$ cells. By selective inhibition of IFN- $\gamma$ through the Jak/stat pathway and by increasing the SLIM, which is ubiquitin E3 ligase for STAT4, it boosts STAT4 protease degradation and reduces IFN- $\gamma$ production [58]. In study Cui et al., it was found that berberine reduced the differentiation of Th1 and Th17 cells by reducing the expression of lineage markers. The berberine inhibits the differentiation to Th17 by activating ERK1/2. ERK plays this role by decreasing the STAT3 phosphorylation and expressing ROR $\gamma$ t. Berberine also inhibits the differentiation of Th1 by inhibiting the activity of p38 MAPK and JNK. Berberine reduces STAT1 and STAT4 activities by suppressing p38 MAPK and JNK activity and controls the stability of STAT4 through the ubiquitin proteasome pathway [42].

However, the response shift mechanism of Th2 in the study of Marinova et al. was rejected because in their study berberine reduced the number of TCD8+ and TCD4+ lymphocytes in mice, which showed suppression of both Th1 and Th2 cells. The suppression of Th1 response in this study was confirmed by inhibiting the delayed type hypersensitivity in TIN+BB mice and suppression of the Th2 response by decreasing the amount of IL-6 in the studied animals [48].

Another mechanism that is effective in berberine's immunomodulatory effect is the involvement of APCs. By reducing the activity of NF- $\kappa \mathrm{B}$ and thus reducing the supply of stimulatory stimulant molecules such as CD80 and CD86 on APCs, berberine reduces antigen delivery performance in these cells. Berberine also suppresses the production of IL-6, IL-12p40, and IL-23p19 in APCs. In confirmation of these findings, $\mathrm{Hu}$ et al. showed that berberine can limit the maturity of DCs and reduce their longevity by inducing selective apoptosis. Berberine can lead to oxygen free radical production, activation of caspase- 3 , and polarization loss in the mitochondrial membrane of DCs, which together result in the apoptosis of these cells [51].

But Jiang et al. presented another mechanism for the anti-inflammatory and immunosuppressive properties of berberine. The purpose of these researchers was to evaluate the protective effects of berberine on neural cells of the brain parenchyma in EAE mice, and they reported that berberine can reduce MMP9 activity in EAE mice, and by decreasing the expression of MMP9, it decreases laminin decomposition and thereby preserves the blood brain barrier, resulting in a reduction in the number of inflammatory cells infiltrated in the brain and reduced expression of inflammatory cytokines in the brain [50].

\section{Conclusion}

It seems that $B$. vulgaris and its most important component berberine play their anti-inflammatory and immunomodulatory effect through the shift of cell immune response to Th2, $\mathrm{T}$ reg induction, inhibition of inflammatory cytokines (IL-1, TNF, and IFN- $\gamma$ ), and stimulation of IL-4 and IL-10. The induction of apoptosis in APCs and other effector cells was another important mechanism. Berberine has showed to have several pharmacological properties, including antimicrobial, anticancer, and immunomodulatory activities. However, hypocholesterolemic and hypoglycaemic activities of berberine have come to light recently. Furthermore, berberine seems to have useful effects on the cardiovascular system, owing to its vase-relaxing and hypotensive activities, as well as the potency of prevention of congestive heart failure, cardiac hypertrophy, and arrhythmia. The experimental and clinical evidence available to date in the literature shows interesting employment prospects of berberine in the treatment of hypercholesterolemia and diabetes. This could open the way not only to a new therapeutic possibility effective in the control of hypercholesterolemia in patients who do not tolerate statins but also to new forms of diabetes therapy and all those situations characterized by evident signs of metabolic syndrome, with possible reduction of a cardiovascular risk. In the end, it is recommended to test and apply these effective compounds in the pharmaceutical industry to control both inflammatory and autoimmune and metabolic diseases.

\section{Conflicts of Interest}

The authors declare that they have no conflict of interest. 


\section{Authors' Contributions}

Rasool Nasiri Kalmarzi and Seyyed Nima Naleini contributed equally to this manuscript.

\section{Acknowledgments}

The authors appreciate and thank Dr. Moahammad Firouzbakht for his cooperation in the draft editing.

\section{References}

[1] W. Kooti, K. Servatyari, M. Behzadifar et al., "Effective medicinal plant in cancer treatment, part 2: review study," Journal of Evidence-Based Complementary \& Alternative Medicine, vol. 22, no. 4, pp. 982-995, 2017.

[2] I. Peluso, M. Palmery, N. S. Yarla, G. Perry, and M. A. Kamal, "From oxidative stress to ageing via lifestyle, nutraceuticals, polypharmacy, and neuropsychological factors," Oxidative Medicine and Cellular Longevity, vol. 2018, Article ID 6352689, 2 pages, 2018.

[3] W. Kooti, Z. Hasanzadeh-Noohi, N. Sharafi-Ahvazi, M. AsadiSamani, and D. Ashtary-Larky, "Phytochemistry, pharmacology, and therapeutic uses of black seed (Nigella sativa)," Chinese Journal of Natural Medicines, vol. 14, no. 10, pp. 732-745, 2016.

[4] W. Kooti, M.-T. Moradi, S. Ali-Akbari, N. Sharafi-Ahvazi, M. Asadi-Samani, and D. Ashtary-Larky, "Therapeutic and pharmacological potential of Foeniculum vulgare Mill: a review," Journal of HerbMed Pharmacology, vol. 4, 2014.

[5] M. Bahmani, A. Zargaran, and M. Rafieian-Kopaei, "Identification of medicinal plants of Urmia for treatment of gastrointestinal disorders," Revista Brasileira de Farmacognosia, vol. 24, no. 4, pp. 468-480, 2014

[6] W. Kooti, S. Ali-Akbari, M. Asadi-Samani, H. Ghadery, and D. Ashtary-Larky, "A review on medicinal plant of Apium graveolens," Advanced Herbal Medicine, vol. 1, no. 1, pp. 4859,2015

[7] W. Kooti, M. Ghasemiboroon, A. Ahangarpoor et al., "The effect of hydro-alcoholic extract of celery on male rats in fertility control and sex ratio of rat offspring," Journal of Babol University of Medical Sciences, vol. 16, no. 4, pp. 43-49, 2014.

[8] F. Farokhi, N. Kafash-farkhad, and M. Asadi-Samani, "Preventive effects of hydro-alcoholic extract of Prangos ferulacea (L.) Lindl. on kidney damages of diabetic rats induced by alloxan," Journal of Shahrekord University of Medical Sciences, vol. 14, no. 6, pp. 72-81, 2013.

[9] M. Bahmani, A. Zargaran, M. Rafieian-Kopaei, and K. Saki, "Ethnobotanical study of medicinal plants used in the management of diabetes mellitus in the Urmia, Northwest Iran," Asian Pacific Journal of Tropical Medicine, vol. 7, Supplement 1, pp. S348-SS54, 2014.

[10] W. Kooti, M. Ghasemiboroon, M. Asadi-Samani et al., "The effects of hydro-alcoholic extract of celery on lipid profile of rats fed a high fat diet," Advances in Environmental Biology, vol. 8, pp. 325-330, 2014.

[11] K. Saki, M. Bahmani, and M. Rafieian-Kopaei, "The effect of most important medicinal plants on two importnt psychiatric disorders (anxiety and depression)-a review," Asian Pacific Journal of Tropical Medicine, vol. 7, Supplement 1, pp. S34S42, 2014.
[12] N. Jafarpoor, S. Abbasi-Maleki, M. Asadi-Samani, and M. H. Khayatnouri, "Evaluation of antidepressant-like effect of hydroalcoholic extract of Passiflora incarnata in animal models of depression in male mice," Journal of HerbMed Pharmacology, vol. 3, 2014.

[13] H. Nasri, M. Rafieian-kopaei, M. Shirzad, M. Rafieian, N. Sahinfard, and S. Rafieian, "Effects of Allium sativum on liver enzymes and atherosclerotic risk factors," Journal of HerbMed Pharmacology, vol. 2, pp. 23-28, 2013.

[14] M. Ahangar Darabi, M. Setorki, and M. Rafieian-Kopaei, "The effect of silymarin on liver injury induced by Thioacetamide in rats," Journal of HerbMed Pharmacology, vol. 2, 2013.

[15] K. Saki, M. Bahmani, M. Rafieian-Kopaei et al., "The most common native medicinal plants used for psychiatric and neurological disorders in Urmia city, northwest of Iran," Asian Pacific Journal of Tropical Disease, vol. 4, pp. S895-S901, 2014.

[16] J. Friedman, "Teratology society: presentation to the FDA public meeting on safety issues associated with the use of dietary supplements during pregnancy," Teratology, vol. 62, no. 2, pp. 134-137, 2000.

[17] D. Bhardwaj and N. Kaushik, "Phytochemical and pharmacological studies in genus Berberis," Phytochemistry Reviews, vol. 11, no. 4, pp. 523-542, 2012.

[18] F. Shamsa, A. Ahmadiani, and R. Khosrokhavar, "Antihistaminic and anticholinergic activity of barberry fruit (Berberis vulgaris) in the guinea-pig ileum," Journal of Ethnopharmacology, vol. 64, no. 2, pp. 161-166, 1999.

[19] M. Aghbashlo, M. H. Kianmehr, and S. R. Hassan-Beygi, "Specific heat and thermal conductivity of berberis fruit (Berberis vulgaris)," American Journal of Agricultural and Biological Sciences, vol. 3, no. 1, pp. 330-336, 2008.

[20] Y. Aynehchi, Pharmacognosy and Medicinal Plants of Iran, Tehran University, 1986.

[21] H.-P. Dorfler and G. Roselt, Dictionary of Healing Plants, Blandford Press, 1989.

[22] Z. Shinwari, A. Khan, T. Nakaike, and N. Kyōkai, Medicinal and Other Useful Plants of District Swat, Pakistan, Al-Aziz Communications, Peshawar, 2003.

[23] M. Imanshahidi and H. Hosseinzadeh, "Pharmacological and therapeutic effects of Berberis vulgaris and its active constituent, berberine," Phytotherapy Research, vol. 22, no. 8, pp. 999-1012, 2008.

[24] K. Usmanghani, A. Saeed, and M. T. Alam, Indusyunic Medicine, Department of Pharmacognosy, Faculity of Pharmacy, University of Karachi, Pakistan, 1997.

[25] J. A. Duke, Handbook of Medicinal Herbs, CRC press, 2002.

[26] M. Blumenthal and W. R. Busse, The Complete German Commission E Monographs: Therapeutic Guide to Herbal Medicines, Lippincott Williams \& Wilkins, 1998.

[27] M. S. Arayne, N. Sultana, and S. S. Bahadur, "The Berberis story: Berberis vulgaris in therapeutics," Pakistan Journal of Pharmaceutical Sciences, vol. 20, no. 1, pp. 83-92, 2007.

[28] N. Ivanovska and S. Philipov, "Study on the anti-inflammatory action of Berberis vulgaris root extract, alkaloid fractions and pure alkaloids," International Journal of Immunopharmacology, vol. 18, no. 10, pp. 553-561, 1996.

[29] E. Küpeli, M. Koşar, E. Yeşilada, and K. H. C. Başer, "A comparative study on the anti-inflammatory, antinociceptive and antipyretic effects of isoquinoline alkaloids from the roots of Turkish Berberis species," Life Sciences, vol. 72, no. 6, pp. 645-657, 2002. 
[30] F. R. Stermitz, P. Lorenz, J. N. Tawara, L. A. Zenewicz, and K. Lewis, "Synergy in a medicinal plant: antimicrobial action of berberine potentiated by $5^{\prime}$-methoxyhydnocarpin, a multidrug pump inhibitor," Proceedings of the National Academy of Sciences of the United States of America, vol. 97, no. 4, pp. 1433-1437, 2000.

[31] L. S-y, L.-H. Ling, B. S. Teh, W. K. Seow, and Y. H. Thong, "Anti-inflammatory and immunosuppressive properties of the bis-benzylisoquinolines: in vitro comparisons of tetrandrine and berbamine," International Journal of Immunopharmacology, vol. 11, no. 4, pp. 395-401, 1989.

[32] P. A. De Smet, K. Keller, R. Hänsel, and R. F. Chandler, Adverse Effects of Herbal Drugs, Springer, 1992.

[33] A. Sharifi, S. A. Mortazavi, A. Maskooki, M. Niakousari, and A. Elhamirad, "Optimization of subcritical water extraction of bioactive compounds from barberry fruit (Berberis vulgaris) by using response surface methodology," International Journal of Agriculture and Crop Sciences, vol. 6, no. 2, p. 89, 2013.

[34] Y. Gilgun-Sherki, E. Melamed, and D. Offen, "Oxidative stress induced-neurodegenerative diseases: the need for antioxidants that penetrate the blood brain barrier," Neuropharmacology, vol. 40, no. 8, pp. 959-975, 2001.

[35] J. Camps, M. Cabr, A. Paul, and J. Joven, "Hepatic paraoxonase activity alterations and free radical production in rats with experimental cirrhosis," Metabolism-Clinical and Experimental, vol. 50, no. 9, pp. 997-1000, 2001.

[36] H. Tomosaka, Y. W. Chin, A. A. Salim, W. J. Keller, H. Chai, and A. D. Kinghorn, "Antioxidant and cytoprotective compounds from Berberis vulgaris (barberry)," Phytotherapy Research, vol. 22, no. 7, pp. 979-981, 2008.

[37] F. Cohen-Boulakia, P. E. Valensi, H. Boulahdour et al., "In vivo sequential study of skeletal muscle capillary permeability in diabetic rats: effect of anthocyanosides," Metabolism-Clinical and Experimental, vol. 49, no. 7, pp. 880-885, 2000.

[38] S. Meiers, M. Kemény, U. Weyand, R. Gastpar, E. von Angerer, and D. Marko, "The anthocyanidins cyanidin and delphinidin are potent inhibitors of the epidermal growth-factor receptor," Journal of Agricultural and Food Chemistry, vol. 49, no. 2, pp. 958-962, 2001.

[39] P. Hanachi, S. Kua, R. Asmah, G. Motalleb, and O. Fauziah, "Cytotoxic effect of Berberis vulgaris fruit extract on the proliferation of human liver cancer cell line (HepG2) and its antioxidant properties," International Journal of Cancer Research, vol. 2, pp. 1-9, 2006.

[40] M. Zovko Končić, D. Kremer, K. Karlović, and I. Kosalec, "Evaluation of antioxidant activities and phenolic content of Berberis vulgaris L. and Berberis croatica Horvat," Food and Chemical Toxicology, vol. 48, no. 8-9, pp. 2176-2180, 2010.

[41] N. Ivanovska, S. Philipov, and M. Hristova, "Influe of Berberine on T-cell mediated immunity," Immunopharmacology and Immunotoxicology, vol. 21, no. 4, pp. 771-786, 1999.

[42] G. Cui, X. Qin, Y. Zhang, Z. Gong, B. Ge, and Y. Q. Zang, "Berberine differentially modulates the activities of ERK, p38 MAPK, and JNK to suppress Th17 and Th1 T cell differentiation in type 1 diabetic mice," Journal of Biological Chemistry, vol. 284, no. 41, pp. 28420-28429, 2009.

[43] A. Zargari, Medicinal Plants, University of Tehran Pub, Tehran, Iran, 6th edition, 2002.

[44] S. Kumar and D. Kumar, "Evaluation of antioxidant potential, phenolic and flavonoid contents of hibiscus liliaceous flowers," EJAF CHE, vol. 7, no. 4, pp. 2863-2871, 2008.
[45] K. Fukuda, Y. Hibiya, M. Mutoh, M. Koshiji, S. Akao, and H. Fujiwara, "Inhibition of activator protein 1 activity by Berberine in human hepatoma cells," Planta Medica, vol. 65, no. 4, pp. 381-383, 1999.

[46] W.-C. Lin and J.-Y. Lin, "Berberine down-regulates the Th1/Th2 cytokine gene expression ratio in mouse primary splenocytes in the absence or presence of lipopolysaccharide in a preventive manner," International Immunopharmacology, vol. 11, no. 12, pp. 1984-1990, 2011.

[47] C.-H. Lee, J.-C. Chen, C.-Y. Hsiang, S.-L. Wu, H.-C. Wu, and T.-Y. Ho, "Berberine suppresses inflammatory agents-induced interleukin- $1 \beta$ and tumor necrosis factor- $\alpha$ productions via the inhibition of $\mathrm{I} \kappa \mathrm{B}$ degradation in human lung cells," Pharmacological Research, vol. 56, no. 3, pp. 193-201, 2007.

[48] E. K. Marinova, D. B. Nikolova, D. N. Popova, G. B. Gallacher, and N. D. Ivanovska, "Suppression of experimental autoimmune tubulointerstitial nephritis in BALB/c mice by berberine," Immunopharmacology, vol. 48, no. 1, pp. 9-16, 2000.

[49] F. Yan, L. Wang, Y. Shi et al., "Berberine promotes recovery of colitis and inhibits inflammatory responses in colonic macrophages and epithelial cells in DSS-treated mice," American Journal of Physiology-Gastrointestinal and Liver Physiology, vol. 302, no. 5, pp. G504-G514, 2012.

[50] Y. Jiang, A. Wu, C. Zhu et al., "The protective effect of berberine against neuronal damage by inhibiting matrix metalloproteinase- 9 and laminin degradation in experimental autoimmune encephalomyelitis," Neurological Research, vol. 35, no. 4, pp. 360-368, 2013.

[51] Z. Hu, Q. Jiao, J. Ding et al., "Berberine induces dendritic cell apoptosis and has therapeutic potential for rheumatoid arthritis," Arthritis and Rheumatism, vol. 63, no. 4, pp. 949959, 2011.

[52] W.-H. Chueh and J.-Y. Lin, "Protective effect of isoquinoline alkaloid berberine on spontaneous inflammation in the spleen, liver and kidney of non-obese diabetic mice through downregulating gene expression ratios of pro-/anti-inflammatory and Th1/Th2 cytokines," Food Chemistry, vol. 131, no. 4, pp. 1263-1271, 2012.

[53] S. Mohebali, S. Nasri, M. Kamalinejhad, and A. S. Noori, "Antinociceptive \& anti-inflammatory effects of Berberis vulgaris L. root's hydroalcoholic extract and determination of it's possible antinociceptive mechanism in male mice," Journal of Paramedical Sciences, vol. 2, no. 4, pp. 12-18, 2011.

[54] T. S. Kim, B. Y. Kang, D. Cho, and S. H. Kim, "Induction of interleukin-12 production in mouse macrophages by berberine, a benzodioxoloquinolizine alkaloid, deviates CD4+ T cells from a Th2 to a Th1 response," Immunology, vol. 109, no. 3, pp. 407-414, 2003.

[55] Z. Kiasalari, M. Khalili, and P. Ahmadi, "Effect of alcoholic extract of Berberis vulgaris fruit on acute and chronic inflammation in male rats," Journal of Babol University of Medical Sciences, vol. 13, no. 58, pp. 28-35, 2011.

[56] L. Xu, Y. Liu, and X. He, "Inhibitory effects of Berberine on the activation and cell cycle progression of human peripheral lymphocytes," Cellular \& Molecular Immunology, vol. 2, no. 4, pp. 295-300, 2005.

[57] M. Aziz, D. Ghareeb, S. Eweda, H. Hussien, and M. E. Demellawy, "Immunomodulatory effect of Berberis vulgaris extracts on murine splenocytes and enrichment of dendritic cells in vitro," Biotechnology \& Biotechnological Equipment, vol. 29, no. 6, pp. 1149-1155, 2015. 
[58] Y. Ren, L. Lu, T. B. Guo et al., "Novel immunomodulatory properties of berbamine through selective down-regulation of STAT4 and action of IFN- $\gamma$ in experimental autoimmune encephalomyelitis," The Journal of Immunology, vol. 181, no. 2, pp. 1491-1498, 2008.

[59] X. Qin, B. T. Guo, B. Wan et al., "Regulation of Th1 and Th17 cell differentiation and amelioration of experimental autoimmune encephalomyelitis by natural product compound berberine," The Journal of Immunology, vol. 185, no. 3, pp. 1855-1863, 2010.

[60] H. Li, X.-L. Li, M. Zhang et al., "Berberine ameliorates experimental autoimmune neuritis by suppressing both cellular and humoral immunity," Scandinavian Journal of Immunology, vol. 79, no. 1, pp. 12-19, 2014.

[61] B. Y. Kang, S. W. Chung, D. Cho, and T. S. Kim, "Involvement of p38 mitogen-activated protein kinase in the induction of interleukin-12 p40 production in mouse macrophages by berberine, a benzodioxoloquinolizine alkaloid," Biochemical Pharmacology, vol. 63, no. 10, pp. 1901-1910, 2002.

[62] H. Mahmoudvand, A. Tavakoli Kareshk, A. Keyhani, N. ZiaAli, and M. R. Aflatoonian, "In vivo evaluation of Berberis vulgaris extract on acute toxoplasmosis in mice," Marmara Pharmaceutical Journal, vol. 21, no. 3, pp. 558-563, 2017.

[63] M. Masoudi, S. Miraj, and M. Rafieian-Kopaei, "Comparison of the effects of Myrtus communis L, Berberis vulgaris and metronidazole vaginal gel alone for the treatment of bacterial vaginosis," Journal of Clinical and Diagnostic Research, vol. 10, no. 3, article QC04, 2016. 


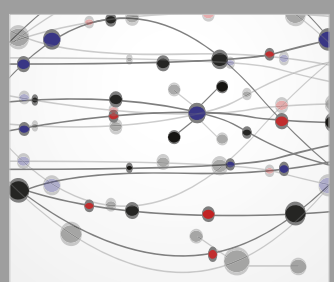

The Scientific World Journal
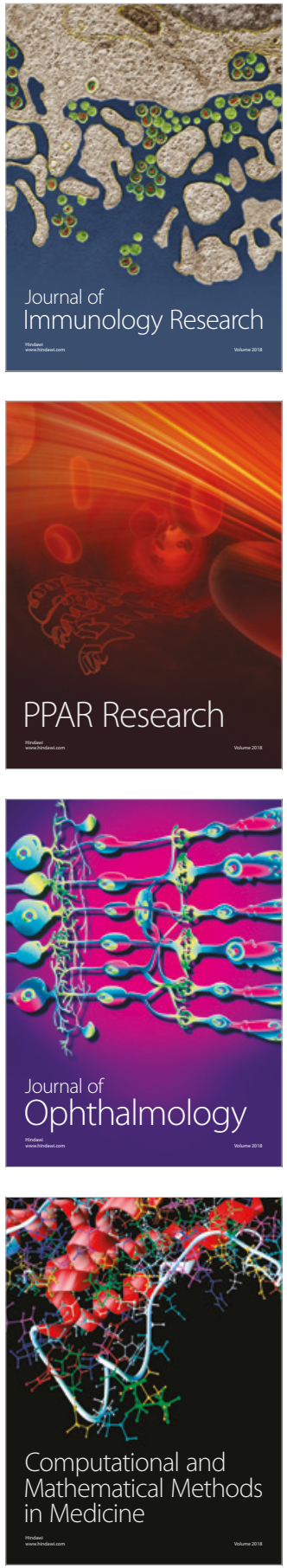

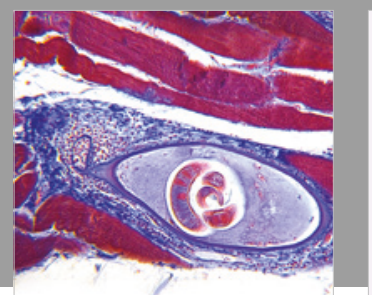

Gastroenterology Research and Practice

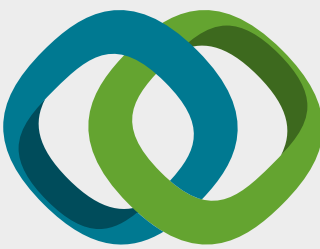

\section{Hindawi}

Submit your manuscripts at

www.hindawi.com
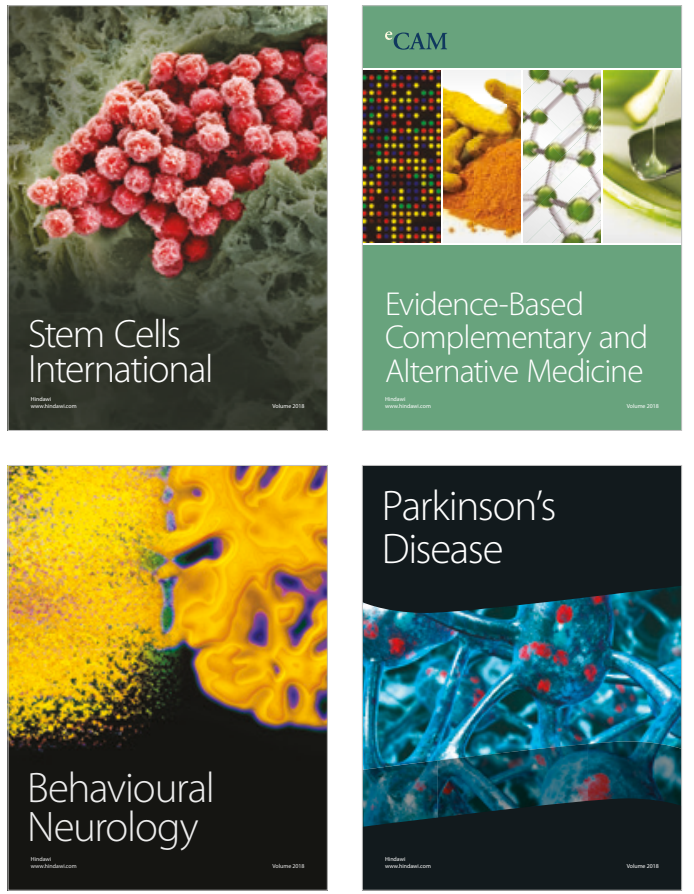

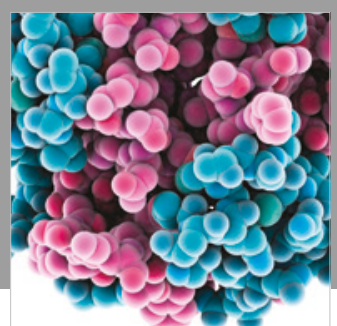

ournal of

Diabetes Research

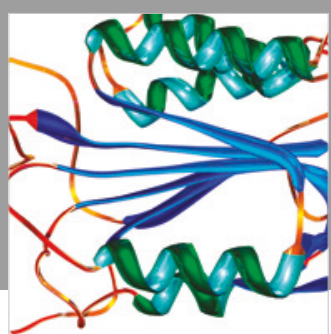

Disease Markers
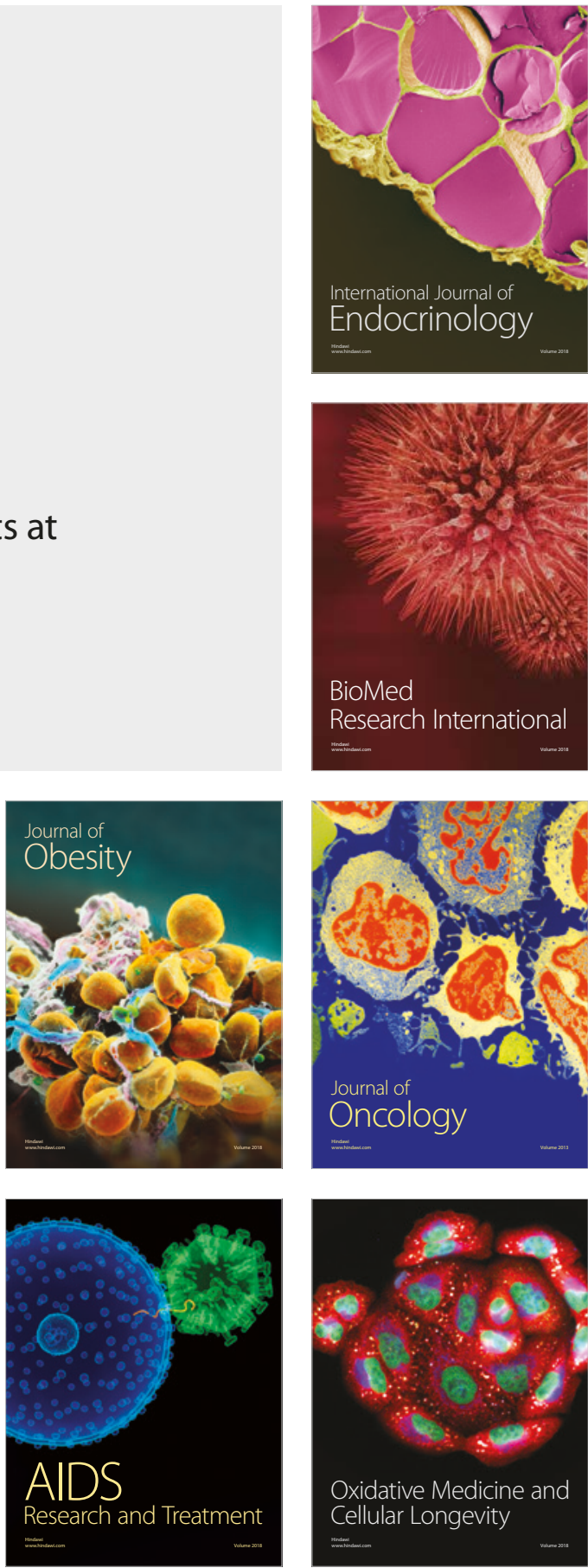